\title{
Nuclear Power: A Hedge Against Uncertain Gas and Carbon Prices
}

\author{
Fabien A. Roques, William J. Nuttall, \\ David M. Newbery and Richard de Neufville
}

November 2005

CWPE 0555 and EPRG 09

These working papers present preliminary research findings, and you are advised to cite with caution unless you first contact the author regarding possible amendments. 


\title{
Nuclear Power: a Hedge against Uncertain Gas and Carbon Prices? ${ }^{1} 2$
}

\author{
Fabien A. Roques* ${ }^{3}$, William J. Nuttall*, David M. Newbery**, Richard de Neufville*** \\ *Judge Business School, University of Cambridge, England \\ **Faculty of Economics, University of Cambridge, England \\ ***Engineering Systems Division, Massachusetts Institute of Technology, USA
}

08 November 2005

\begin{abstract}
High fossil fuel prices have rekindled interest in nuclear power. This paper identifies specific nuclear characteristics making it unattractive to merchant generators in liberalised electricity markets, and argues that non-fossil fuel technologies have an overlooked 'option value' given fuel and carbon price uncertainty. Stochastic optimisation estimates the company option value of keeping open the choice between nuclear and gas technologies. This option value decreases sharply as the correlation between electricity, gas, and carbon prices rises, casting doubt on whether private investors' fuel-mix diversification incentives in electricity markets are aligned with the social value of a diverse fuel-mix.
\end{abstract}

Keywords: Nuclear economics, stochastic optimisation, fuel-mix, diversification.

JEL reference: C15, C61, L52, L94.

\footnotetext{
${ }^{1}$ The authors wish to thank anonymous referees, Dr. Paul Twomey, Dr. Chris Hope, and Stephen Connors for useful comments on earlier drafts.

${ }^{2}$ Data and advice from BNFL are greatly acknowledged, as well as financial support from the CMI Electricity Project. The authors also thank Platts and EEX for providing data on electricity, gas and carbon prices. The usual disclaimer applies.

${ }^{3}$ Judge Business School, University of Cambridge, Trumpington Street, Cambridge, CB2 1AG, England, email: f.roques@jbs.cam.ac.uk; fabien.roques@gmail.com.
} 


\section{INTRODUCTION}

There has been no new nuclear build in the last decade in either Europe or North America. ${ }^{4}$ Over the same period these regions have seen a transition to liberalised markets that has moved electricity from the domain of government industrial policy. Are these observations related? In the U.S., the 'Nuclear 2010 project' supports actions intended to help the private financing of nuclear plant for 2010 (Rothwell et al., 2005). In Europe, both Finland and France are taking the first steps towards new nuclear build. In the latter case we believe this to be an example of the state corporatism of the past, but the Finnish case is more interesting. Much of the conventional debate around nuclear power competitiveness has focussed on the expected levelised cost of nuclear power compared to other forms of base-load generation. Higher fossil fuel and carbon prices are changing attitudes towards nuclear generation in general and nuclear merchant generation in particular.

This paper tackles the question as to whether an electricity utility of merchant investors might choose to add a nuclear power plant to their generation capacity in order to hedge against the risks of volatile prices for fossil fuels (natural gas) or for carbon dioxide emissions. We conclude that for likely commercial costs of capital such option values are severely eroded by higher correlations between gas fuel, carbon emission and electricity prices. As there is likely to be a social and consumer benefit in fuel mix diversity, this paper will show that current liberalised electricity markets appear to lack incentives for utilities and merchant generators to add to fuel mix diversity by constructing new nuclear power plants. Such considerations are extremely topical in the USA, the UK and other countries considering policy options for clean and secure energy supplies in their liberalised electricity markets.

The rest of the paper is organised as follows. Section two synthesises the results of recent studies on the comparative economics of nuclear and its main competitor, Combined Cycle Gas Turbines (CCGTs), and details the different features of a liberalised electricity industry that adversely impact on the competitiveness of nuclear power. Section three argues that nuclear and non-fossil fuel technologies have an 'option value' for a utility as they mitigate against fuel and carbon price uncertainty in a way not recognised by traditional valuation approaches. A 5-plant utility investment plan using a stochastic optimisation model is presented, which provides an estimate of the option value for the utility to retain the ability to choose between nuclear and CCGT technologies for its future investments. Section five concludes by discussing the model results' implications for technology diversification in electricity markets.

\footnotetext{
${ }^{4}$ In 2005 about 30 power reactors are being constructed in 11 countries, notably China, the Republic of Korea, Japan and Russia (World Nuclear Association, 2005).
} 


\section{NUCLEAR ECONOMICS IN LIBERALISED ELECTRICITY MARKETS}

In 2005 there were 440 nuclear power reactors in 31 countries, with a combined capacity of 367 GWe, generating some $16 \%$ of the world's electricity (WNA, 2005). Until recently, however, no new nuclear power station had been commissioned in a liberalised electricity industry. One key issue for the commercial future of nuclear power is to understand how the commercial unattractiveness of nuclear power is related to electricity market structures. To what extent has the risk redistribution in the liberalised electricity industry and the resulting higher cost of capital contributed to the success of gas-fired plants to the detriment of nuclear power and other capital-intensive technologies?

\subsection{Levelised cost comparisons}

The traditional approach for comparing the competitiveness of different generation technologies is the 'levelised cost' methodology, based on a discounted cash flow analysis (DCF) over the life of the plant. This valuation technique is appealing as it gives simple results in the form of comparable levelised production costs. The levelised cost approach was well suited to the stable environment of the electricity industry before liberalisation. It continues to be widely used by utilities post liberalisation, despite its inappropriateness for evaluating investment choices under uncertainty (Deutch et al 2003, IEA, 2005).

Table 1 shows the model parameters and levelised costs for the most recent studies conducted in Belgium (Ampere, 2000), the U.K. (RAE, 2004), Finland (Tarjanne and Rissanen, 2000), France (Dideme, 2003), and the USA (Deutch et al., 2003, and Tolley et al., 2004). The table shows wide differences in the results, arising mainly from the different assumptions made for construction and operating costs of nuclear and the differing financing structures of the models. The important differences in the costs estimates for new nuclear build can be traced back to different assumptions on two key factors: first, the reported construction cost for new capacities exceeding 1000 MWe ranges from $£ 900 / \mathrm{kWe}$ to $£ 1,400 / \mathrm{kWe}$. Second, the financing assumptions differ greatly (real discount rates varying from $5 \%$ to $12.5 \%$, equity shares varying from $30 \%$ to $50 \%$, and debt repayments concentrated in the first 10 years or spread over the life of the plant (Deutch et al., 2003, Tolley et al., 2004)). These different assumptions reveal not only different degrees of confidence in the nuclear industry cost figures, but also a different understanding of the impact of the electricity industry liberalisation on new nuclear plants economics and financing. 
Table 1 - International comparison of levelised cost estimates for nuclear and CCGTs.

\begin{tabular}{|c|c|c|c|c|c|c|c|c|c|c|c|c|}
\hline Study & \multicolumn{2}{|c|}{$\begin{array}{l}\text { Belgium } \\
\text { (Ampere) }\end{array}$} & \multicolumn{2}{|c|}{$\begin{array}{c}\text { Finland } \\
\text { (Tarjanne) }\end{array}$} & \multicolumn{2}{|c|}{$\begin{array}{c}\text { France } \\
\text { (DGEMP) }\end{array}$} & \multicolumn{2}{|c|}{$\begin{array}{c}\text { UK } \\
\text { (RAE) }\end{array}$} & \multicolumn{2}{|c|}{$\begin{array}{c}\text { USA } \\
\text { (Deutch et al., } \\
\text { MIT) }\end{array}$} & \multicolumn{2}{|c|}{$\begin{array}{l}\text { USA (Tolley et } \\
\text { al., University of } \\
\text { Chicago) }\end{array}$} \\
\hline Date & \multicolumn{2}{|c|}{2000} & \multicolumn{2}{|c|}{2001} & \multicolumn{2}{|c|}{2003} & \multicolumn{2}{|c|}{2004} & \multicolumn{2}{|c|}{2003} & \multicolumn{2}{|c|}{2004} \\
\hline & Nuclear & CCGT & Nuclear & CCGT & Nuclear & CCGT & Nuclear & CCGT & Nuclear & CCGT & Nuclear & CCGT \\
\hline Capacity factor & \multicolumn{2}{|c|}{$85 \%$} & \multicolumn{2}{|c|}{$85 \%$} & \multicolumn{2}{|c|}{$85 \%$} & \multicolumn{2}{|c|}{$85 \%$} & \multicolumn{2}{|c|}{$85 \%$} & \multicolumn{2}{|c|}{$85 \%$} \\
\hline $\begin{array}{l}\text { Construction } \\
\text { time (years) }\end{array}$ & 5 & 2 & 5 & 2 & 5 & 2 & 5 & 2 & 5 & 2 & 5 & 3 \\
\hline $\begin{array}{c}\text { Discount rate } \\
\text { (real) }\end{array}$ & \multicolumn{2}{|c|}{$5 \%$} & \multicolumn{2}{|c|}{$5 \%$} & \multicolumn{2}{|c|}{$8 \%$} & \multicolumn{2}{|c|}{$7.5 \%$ (nominal) } & $11.5 \%$ & $9.6 \%$ & $12.5 \%$ & $9.5 \%$ \\
\hline & \multicolumn{12}{|c|}{ Breakdown of levelised cost $(£ / M W h)^{5}$} \\
\hline Investment $^{6}$ & 14.4 & 7.8 & 9.7 & 3.9 & 11.2 & 4.3 & 13.9 & 3.8 & - & - & - & - \\
\hline O\&M & \multirow[t]{2}{*}{6.6} & \multirow[t]{2}{*}{15.0} & 5.0 & 1.1 & 3.5 & 2.8 & 5.6 & 3.4 & - & - & - & 1.4 \\
\hline Fuel & & & 2.1 & 17.6 & 3.1 & 15.0 & 4.2 & 15.5 & - & - & 2.4 & 13 \\
\hline Taxes & - & - & - & - & 1.8 & 2.4 & - & - & - & - & - & - \\
\hline R\&D & - & - & - & - & 0.4 & - & - & - & - & - & - & - \\
\hline $\begin{array}{c}\text { Total levelised } \\
\text { cost }\end{array}$ & 21 & 22.8 & 16.8 & 22.5 & 19.9 & 24.2 & 23.7 & 22.6 & 36.9 & 21 to 31 & $\begin{array}{c}26-341^{\text {st }} \\
\text { unit; } 19- \\
22 \\
5^{\text {th }} \text { unit }^{7}\end{array}$ & 19 to 25 \\
\hline
\end{tabular}

\subsection{Biases against nuclear power in liberalised electricity markets}

When examining the alleged discrimination in technology choice caused by market liberalisation, one should remember that the old regulated vertically integrated monopoly model also introduced biases. It was normally able to finance any required capacity in generation, but provided poor incentives for delivering investment in a timely and costeffective way. Averch and Johnson (1962) demonstrated that regulated utilities might rationally prefer to invest in excessively capital-intensive technologies. Moreover, the subordination of utilities to regulation bodies gave rise to other distortions of investment choices. For instance, many countries directly controlled or influenced the fuel mix through subsidies to 'national' fuels (such as coal or lignite), or the financing of 'national' technologies (such as nuclear) (Newbery and Green, 1996).

In liberalised markets investments are profit motivated, with the choice of technology left to the market. The redistribution of risk among the different stakeholders is likely to make nuclear generation unattractive for an investor, even when its levelised costs are similar to the levelised costs of the dominant technology, for several reasons.

\footnotetext{
${ }^{5}$ The exchange rate used in this paper is 1 Euro $=£ 0.7$ and 1 US $\$=£ 0.55$.

${ }^{6}$ Nuclear investment costs include spent fuel management, plant decommissioning and final waste disposal. Decommissioning costs are estimated at $9-15 \%$ of the initial cost of a nuclear power plant, but contribute only a few percent to the investment costs when discounted (in the USA, they account for $0.1-0.2$ cents/KWh). The back-end of the fuel cycle contributes up to another 10\% to the overall costs per KWh (the \$18 billion US spent fuel program is funded by a 0.1 cent/kWh levy) (Uranium Information Center, 2004).

${ }^{7}$ Assuming a (conservative) 3\% learning rate (cost saving by doubling of the number of plants built).
} 
First, investors have a strong preference for a shorter payback period, which makes investments with short lead time more attractive. Nuclear lead times (5 years in the most optimistic scenario in Table 2) are, for engineering and licensing reasons, much longer than CCGT lead times (2 years).

Table 2 - Years Elapsed from Construction Start to Commercial Operation of Nuclear Power Plants. Source: Tolley et al. (2004)

\begin{tabular}{|l|c|c|c|c|c|}
\hline & Average & Minimum & Maximum & $\begin{array}{c}\text { Standard } \\
\text { deviation }\end{array}$ & $\begin{array}{c}\text { Last plant } \\
\text { begun }\end{array}$ \\
\hline U.S nuclear plants connected to grid & 9.3 & 3.4 & 23.4 & 3.8 & 1977 \\
\hline French nuclear plants connected to grid & 6.7 & 4.3 & 16.3 & 2 & 1985 \\
\hline $\begin{array}{l}\text { Plants under construction beginning later } \\
\text { than 1993 }\end{array}$ & 5.3 & 4.5 & 7.2 & 0.75 & 2001 \\
\hline
\end{tabular}

Second, construction costs for nuclear plant are two to four times greater ( $£ 900$ to $£ 1,400$ per kWe installed) than for a CCGT ( $£ 300$ to $£ 500$ per kWe installed). Of the three major components of nuclear generation cost - capital, fuel, and operation and maintenance the capital cost component makes up approximately $60 \%$ of the total, while it only represents about $20 \%$ of total costs for a CCGT (see Table 3). In addition, the size of a typical nuclear unit is much larger than the size of a typical gas turbine: recent nuclear technologies range from 1000MWe (AP1000 from BNFL) to 1600MWe (EPR from Framatome-Siemens), while CCGTs units are only of about 200 to 650 MWe (although it is common to build several on one site). This implies that the required minimum upfront capital investment for a nuclear plant can be ten to fifteen times greater than the smallest investment required for a CCGT. ${ }^{8}$

Table 3 - Comparison of capital intensity of Nuclear and CCGT technologies. Source: Own estimates

\begin{tabular}{|l|c|c|}
\hline Breakdown of MWh cost & Nuclear & Gas CCGT \\
\hline Investment & $50-60 \%$ & $15-20 \%$ \\
\hline O\&M & $20-35 \%$ & $5-10 \%$ \\
\hline Fuel & $15-20 \%$ & $70-80 \%$ \\
\hline
\end{tabular}

Third, the lack of recent experience with new build makes it difficult to get reliable cost estimates. The traditional optimism of nuclear vendors reinforces investors' distrust of vendors' assessments. The history of nuclear electricity includes a list of seriously delayed construction and cost overruns (Nuttall, 2004). Besides, investors must confront the regulatory and political challenges associated with obtaining a license to build and operate a plant on a specific site. In the past, disputes about licensing, local opposition, cooling water

\footnotetext{
${ }^{8}$ NEA (2000) presents a detailed analysis of the most significant means to reduce nuclear plant capital cost with current technologies, such as increased plant size, improved construction methods, reduced construction schedules, standardisation and construction in series, and multiple unit construction.
} 
sources and discharge requirements have delayed construction and completion of nuclear plants both in the US and Europe (Ludwigson et al., 2004).

Fourth, the greater size of nuclear technology exposes investors to greater downside risks, as for the next decade only large-scale Generation III plants (>500MW) are available. In the context of liberalised electricity markets, the uncertainty about electricity price tends to encourage the construction of series of small-scale modular units, as the timing of entry is critical to the returns of an investment. Several units of CCGTs can be built successively on the same generation site, thus allowing the investor to minimise its downside risk by waiting to invest in the final generation capacity. For engineering reasons scale economies dominate nuclear plants and reducing unit size does not appear economic with current 'generation three' technologies. ${ }^{9}$ The development of economically competitive small scale (approximately 200MW) modular nuclear reactors will require new designs, such as the South African Pebble bed reactor or the General Atomic GTHMR (Nuttall, 2004). Such technologies are however unlikely to be ready for commercialisation before the second quarter of the century, and for this reason they are not considered here.

Learning has been demonstrated to play an important role in the nuclear power industry, both for building costs through construction in series, and for operating costs (NEA, 2000). ${ }^{10}$ Learning was facilitated by the pre-liberalisation industrial structure. It is questionable, however, how much of this learning can be achieved under a liberalised industry structure. Lester and McCabe (1993) reveal that the relationship between experience and performance has been strongly influenced by industrial structure. Their study suggests that existing nuclear technology might not be adapted to the fragmented industry structure that resulted from the unbundling and divestures typically associated with liberalisation.

\subsection{The challenges of financing nuclear power}

With its capital intensity and cautionary experiences of engineering difficulties and regulatory creep during construction, new nuclear build will probably require a substantial risk premium over competing technologies (Scully Capital, 2002). Tolley et al. (2004) estimate that the risk premium required by bond and equity holders for financing new nuclear plants is around 3\% higher than for other technologies. Similarly, Deutch et al. (2003) assume that merchant financing of nuclear power would require a 15\% nominal return on equity (as compared to a $12 \%$ nominal return on equity for gas and coal), and a $50 \%$ equity share of financing (as compared to only $40 \%$ equity financing for gas and coal). ${ }^{11}$

\footnotetext{
${ }^{9}$ Gollier et al. (2005) compare the benefit of one large nuclear power plant project coming from increasing returns to scale, to the benefit of a modular sequence of smaller (300 MWe), modular, nuclear power units on the same site, and show that the benefit of modularity is equivalent in terms of profitability to a reduction of the cost of electricity by only one-thousand of a euro per kWh.

${ }^{10}$ France and Japan are typical examples of learning and scale economies resulting from a large nuclear investment program (Tolley et al., 2004).

${ }^{11} \mathrm{EDF}$ is planning to finance the new EPR reactor with a $50 \%$ equity share, an internal return on equity target of 13.7\%, and long term loans at debt interest rates lower than 5\% (IGF-CGM, 2004).
} 
Rothwell et al. (2005) propose a project financing approach using Real Options for a nuclear plant in Texas. They show how a "tollgates approach" with options to defer and abandon the construction project after the site permission and regulatory licensing procedures improves the nuclear plant value. Innovative financing techniques have been investigated to disentangle the high risks associated with new nuclear plant construction from the lower economic risks during plant operations (Tolley et al., 2004). The first prototypes to be built will therefore have a critical importance in demonstrating efficient regulatory screening and site licensing procedures, as well as reducing engineering cost uncertainties, thereby lowering the cost of capital for subsequent units. Such considerations lead some to call for governmentassured loans to compensate for the regulatory hurdles and procedures. Finally, a critical issue for the commercial future of nuclear power will lie in the willingness of large European and American utilities to share the risks and development costs of new nuclear power stations. Cooperative agreements might help to spread costs and risks, but their success will depend on completing a large program of new build, and on achieving operational learning despite fragmented ownership.

Given all these challenges to new nuclear build, what explains the recent decisions to build a new nuclear power unit in Finland (2004) and France (2005)? In Finland, the large capital costs of the plant have been financed by very long-term power purchase agreements. Interest in such long-term agreements, which are rare in liberalised markets, has been triggered by the specificities of local industries that have very long investment cycles and are extremely sensitive to the price of electricity. The Finnish electricity company Teollisuuden Voima Oy (TVO) is a cooperative grouping of local utilities and large industrial consumers, which are mainly paper makers with a very long investment cycle (over 40 years). ${ }^{12}$ Each shareholder will enjoy electricity at production cost during the life of the plant (40 years), i.e. at a very stable price, in proportion to its share, as well as holding a useful option on the future carbon price.

These long-term power purchase agreements enabled financing at low cost ( $5 \%$ real discount rate in the Tarjanne (2000) study that served as basis for the technology choice), which substantially improves nuclear economics. This paper will demonstrate that at more typical real commercial discount rates of $8 \%$ or $10 \%$ nuclear has only a very small option value in markets with high degrees of correlation between natural gas fuel prices, carbon emission charges and the electricity price. The Finnish example reminds us that low discount rates are obtainable in liberalized markets when strategy can be shaped by large, well informed and forward looking electricity consumers with a long-term outlook. It is not impossible to identify such consumers in other liberalized markets, but the dominant assumption is that electricity consumers are generally uninterested in hedging their risk exposure to electricity price fluctuations.

In France, the Government has been exploring different ways to recreate a favourable institutional environment to finance the construction of a 3 billion Euro new nuclear EPR.

\footnotetext{
${ }^{12}$ TVO is a public-private partnership company, $43 \%$ government-owned, $57 \%$ private.
} 
The Government is facilitating the participation of electricity-intensive industries (such as aluminium smelters) in the financing of the EPR demonstrator, through the renewal of the long-term fixed-price contracts for electricity below market price that were signed with Electricite de France (EDF) prior to the opening of the French market (IGF-CGM, 2004). Another way to share the costs and risks associated with the construction of new reactors is to associate foreign utilities with EDF. In return for the agreement of EDF to buy $50 \%$ of the ownership of the much indebted Italian utility Edison, EDF has obtained the participation of ENEL into the financing of the new EPR.

In sum, the Finnish and French cases are in many ways reminiscent of the institutional environment that made nuclear a competitive technology in the days of regulated monopoly (at least for certain fuel price configurations), through the transfer of investment and operation risks to consumers via contractual arrangements.

\subsection{The potential financial benefits of nuclear power}

There are potentially two attributes of nuclear power generation that could make it more appealing to investors. First, nuclear generation costs are insensitive to both gas and carbon price risk (as are most renewables). ${ }^{13}$ Therefore, rising gas prices and carbon trading or carbon taxes will make nuclear more competitive against CCGTs and coal-fired plants. ${ }^{14}$ Second, investing in nuclear provides a hedge against the volatility and risk of gas and carbon prices. The uncertainty over the evolution of gas and carbon prices implies that there is an option value associated with being able to choose between nuclear power and other fossil fuel technologies in the future. Moreover, the hedging value of a nuclear power investment to a company is not restricted to the insensitivity of this plant to gas and carbon prices. For a company already operating some fossil fuel generation plants, investing in a nuclear plant reduces the company's overall exposure to fossil fuel and gas prices.

While most valuation studies of competitive generation technologies take account of different gas and carbon prices through sensitivity analysis (and its more sophisticated variant, Monte Carlo simulation), as far as the authors know, there is no published study valuing nuclear as a hedge against uncertain gas and carbon prices from a company perspective. This 'hedging value' cannot be captured by the standard levelised cost approach, as it requires a dynamic model to capture the option value associated with the flexibility of waiting for more information on gas and carbon prices before making the best informed technology choice. Besides, standard levelised cost studies can only compare different technologies on a stand alone basis, whereas it is also important to consider how the riskreturn profile of the investment affects the overall risk-return profile of the company. In other words, assessing the economics of a nuclear or CCGT power plant investment from a

\footnotetext{
${ }^{13}$ Nuclear fuel price have relatively little effect on electricity generation costs: a doubling of the uranium oxide price would increase the fuel cost for a light water reactor by $30 \%$, and the electricity cost by only about $7 \%$, whereas doubling the gas price would add 70\% to the price of electricity (Uranium Information Center, 2004). ${ }^{14}$ In the EU, $\mathrm{CO}_{2}$ emissions are now priced by the emissions trading scheme.
} 
company perspective requires taking into account the complementarity of the risk-returns profiles of the different technologies that the company operates. ${ }^{15}$

The model presented next quantifies the 'option value' to a company of the ability to choose between a nuclear or a gas-fired plant investment at successive moments in the future, when the company faces stochastic gas, carbon, and electricity prices. The 'nuclear option' therefore corresponds to the technical ability to choose nuclear. ${ }^{16}$ The option value encompasses both the value associated with the ability to wait and observe the evolution of gas and carbon prices, and the 'hedging' or diversification value associated with a more diverse portfolio of production technologies for the company.

\section{THE OPTION VALUE OF NUCLEAR FOR A COMPANY FACING UNCERTAIN ELECTRICITY, GAS AND CARBON PRICES}

Our hypothetical electric company's investment plan consists of building five 1,000 MW power stations over twenty years. The managers face investment decisions in years $0,5,10$, 15 and 20 and choose either a nuclear or in a gas-fired combined cycle gas turbine (CCGT). The managers maximise the expected profitability of their investment, and their choice will depend on the relative prices of electricity, gas and carbon. This investment plan can be interpreted as a strategy to maintain constant production capacity, in the case of a utility replacing its plants as they reach the end of their lives. Alternatively it can model an aggressive expansion strategy for a new entrant in the market that does not operate any generation asset in year 0 .

For a given sample path of stochastic electricity, gas, and carbon prices, the nuclear option value is calculated as the difference between the Net Present Value (NPV) of the investment plan when managers have the choice between investing in a nuclear or a CCGT power plant at each decision point, and the NPV of the default scenario in which managers have no choice and can only invest in a CCGT. The model simulates 100,000 realisations of the stochastic electricity, gas, and carbon prices and their associated NPVs to give a probability distribution for the two NPVs. The probability distribution of the NPV of the nuclear 'option value' corresponds to the difference between these two distributions.

\subsection{Model general settings}

Most Real Options models use a continuous time partial differential equations which can yield elegant closed form solutions, but which suffer from the drawback that they are limited

\footnotetext{
${ }^{15}$ Awerbuch and Berger (2003) apply portfolio theory to identify Europe's best fuel mix at the macro-economic level.

${ }^{16}$ In contrast to a CCGT plant, operating a nuclear plant requires a dedicated set of skills to address the specific technological, regulatory and legal issues related to this technology, which could get lost if no investment was made for a long time. Stenzel (2003) details the different challenges associated with 'keeping the nuclear option open' in the UK.
} 
to relatively stylised settings if they are to remain tractable (Dixit and Pindyck, 1994). Murto and Nese (2002), Pindyck (1993), and Gollier et al. (2005) use such an approach to study respectively the impact of input price risk, construction cost risk, or construction modularity on investors' technological choices. Rothwell et al. (2005) use a Real Options approach to value the managerial flexibility to defer and abandon a nuclear plant construction if the site selection and regulatory licensing procedures are unsuccessful.

An alternative approach is to use a discrete time approximation using a simple binomial process (Cox et al. 1979). This approach is more appealing to industry practitioners, insofar as it can be implemented in a spreadsheet, and enables a more realistic representation of real-world problems (Frayer and Uludere, 2001). It faces the problem that solutions can become difficult to find with more than one stochastic parameter, when the stochastic parameters do not follow a random walk, and when parameters are correlated.

Our model differs from these approaches in several respects. It includes a very detailed description of the cost and technical specificities associated with each technology, a realistic evolution of stochastic electricity, gas, and carbon prices based on industry forecasts, and a tractable investment decision rule using observations to date that represents investment behaviour under limited information.

\subsubsection{Cost and technical parameters}

The parameters of the model correspond to technologies available by 2010 for new build in the U.K. and are summarised in Table 4. All the costs are expressed in real 2005 British Pounds. Cost and technical parameters are derived from the MIT Future of Nuclear Power study (Deutch et al., 2003), updated with the International Energy Agency Costs of Generating Electricity (2005), and with the data on the AP1000 reactor system from BNFL. Sensitivity analyses to each cost and technical parameters have been carried out and are presented in the Appendix.

The model provides a fairly realistic description of the specificities associated with an investment in either a CCGT plant or a nuclear power plant. For example, the investment lag is five years in the case of nuclear, while it is only two years in the case of the CCGT plant. ${ }^{17}$ Bar-Ilan and Strange (1996) have showed that investment lags can have an important effect on investment decisions under uncertainty. A sensitivity analysis of the results of the model to different construction times for nuclear and CCGT plants is presented in the Appendix. Moreover, the nuclear plant is expected to operate for longer (40 years) than the CCGT plant (30 years).

The capital costs ('overnight cost' and 'O\&M incremental cost') are much higher for the nuclear plant than for the CCGT plant, while the converse is true for fuel costs. Construction time and plant life are longer for a nuclear plant than for a CCGT. Nuclear plant

\footnotetext{
${ }^{17}$ These investment lags are estimates of the construction times, assuming that the construction permit and regulatory approval have been obtained.
} 
incurs a 'nuclear waste fee' to cover the cost of decommissioning and nuclear waste treatment. These critical parameters are subject to a sensitivity analysis reported in the Appendix. The cost of $\mathrm{CO}_{2}$ emissions related to the European Emission Trading Scheme is represented by a 'carbon tax'.18

Table 4 - Technical and Cost Parameters

\begin{tabular}{|c|c|c|c|}
\hline Parameters & Unit & Nuclear & CCGT \\
\hline \multicolumn{4}{|l|}{ Technical parameters } \\
\hline Net capacity & Mwe & 1000 & 1000 \\
\hline Capacity factor & $\%$ & $85 \%$ & $85 \%$ \\
\hline Heat rate & $\mathrm{BTU} / \mathrm{kWh}$ & 10400 & 7000 \\
\hline Carbon intensity & $\mathrm{kg}-\mathrm{C} / \mathrm{mmBTU}$ & 0 & 14.5 \\
\hline Construction period & Years & 5 & 2 \\
\hline Plant life & Years & 40 & 30 \\
\hline \multicolumn{4}{|c|}{ Cost parameters (Real $2005 £$ ) } \\
\hline Overnight cost & $£ / K W e$ & 1140 & 285 \\
\hline Incremental capital costs & £/KWe/year & 11.4 & 3.4 \\
\hline Fixed O\&M & $£ /$ KWe/year & 36 & 9 \\
\hline Variable O\&M & $\mathrm{p} / \mathrm{KWe}$ & 2.3 & 3 \\
\hline O\&M real escalation rate & $\%$ & $1.00 \%$ & $1.00 \%$ \\
\hline Nuclear waste fee & $\mathrm{p} / \mathrm{KWh}$ & 6 & 0 \\
\hline \multicolumn{4}{|l|}{ Financing parameters } \\
\hline Real WACC & $\%$ & $10 \%$ & $10 \%$ \\
\hline Marginal Corporate Tax & $\%$ & $30 \%$ & $30 \%$ \\
\hline \multicolumn{4}{|l|}{ Market prices } \\
\hline Carbon tax & $£ / \mathrm{tC}$ & \multirow{3}{*}{\multicolumn{2}{|c|}{ See next section }} \\
\hline Fuel costs & p/therm & & \\
\hline Electricity price & $\mathrm{p} / \mathrm{KWh}$ & & \\
\hline
\end{tabular}

Both plants are assumed to operate base-load with an average annual capacity utilisation factor of $85 \% .{ }^{19}$ The operating flexibility of the CCGT plant is explicitly modelled by assuming that it can stop generating whenever electricity, gas, and carbon prices make it uneconomic. Due to engineering constraints and the low marginal costs of production, it seems a realistic assumption to assume that the nuclear plant always produces at maximum output.

The financing structure of the model is kept simple, with a corporation tax rate of $30 \%$ and three scenarios for the real weighted average cost of capital (WACC) of 5\%, $8 \%$ and $10 \%$. The latter two appear more realistic for merchant investment, although the special

\footnotetext{
${ }^{18}$ Note that to express this as a cost per tonne of $\mathrm{CO}_{2}$ multiply by 3.67 .

${ }^{19}$ This value represents a low estimate for nuclear (most nuclear plants are currently running at a capacity factor higher than $90 \%$ in Europe and in the US), but a relatively high estimate for gas which might be cycling up and down.
} 
contractual agreement in the Finnish case described in the previous section has enabled the economic planning study to use a 5\% real discount rate (Tarjanne and Rissanen, 2000). Again this is subject to a sensitivity analysis reported below in the Appendix.

\subsubsection{Stochastic gas, carbon and electricity prices}

When modelling commodity prices, it is important to distinguish price variability from price risk. In the case of electricity, price variability corresponds to usual daily and seasonal fluctuation patterns which are easy to forecast (Geman, 2005). Uncertainty about prices can in turn be decomposed into short-term risk due to unexpected events (e.g. plant or transmission line breakdowns and weather unpredictability), and long-term trend risk, corresponding to the difficulty of predicting accurately supply and demand growth.

The stochastic process used to generate electricity, gas and carbon prices in our model does not represent daily and seasonal variations, as broadly these are foreseeable by investors. The model concentrates on price risk and models both medium and long-term trend risk. The assumption that prices follow a simple random walk (as is standard in Real Option models) might be reasonable when studying short-term operating decisions, it does not seem realistic when considering long-term investment decisions in the electricity industry. The present model instead assumes both long-term trend risk and medium-term (yearly) risk, giving a more realistic description of the risks facing long-lived investments in electricity markets. The electricity, gas, and carbon prices are based on current projections, and capture the range of values likely looking forward.

Figure 1: Projected and realised electricity prices (p/kWh)

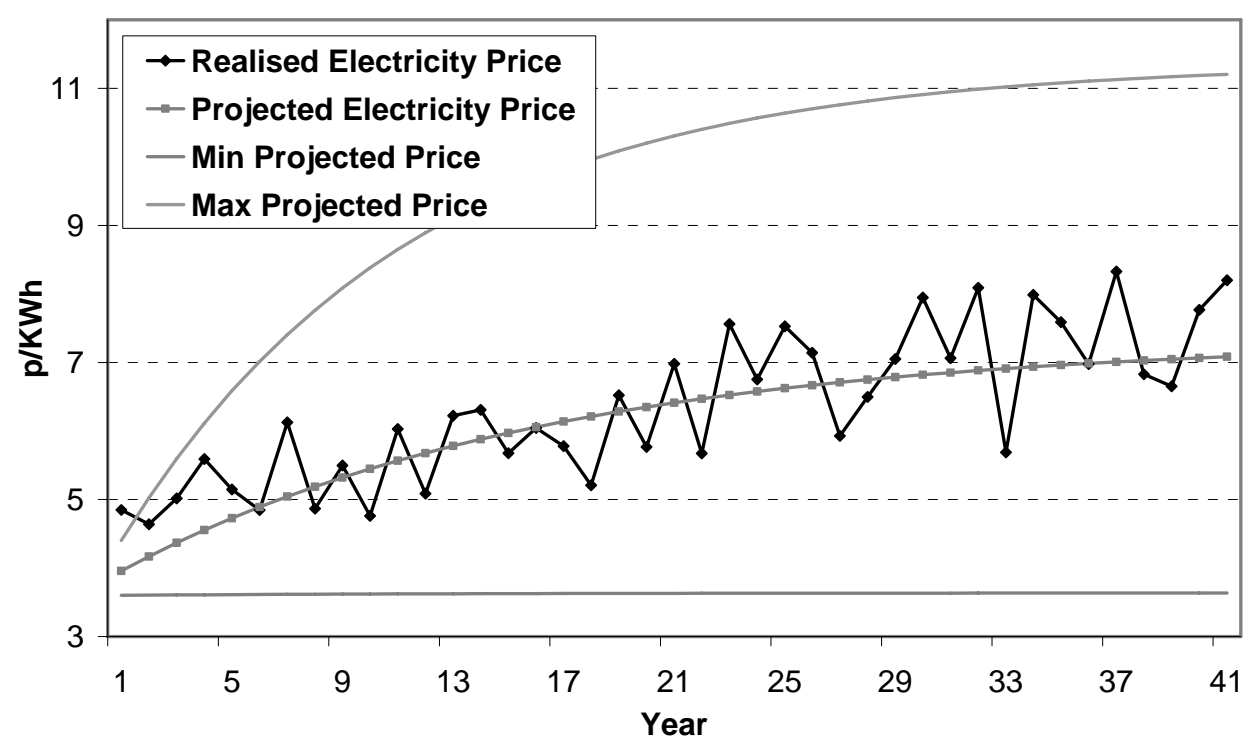

The long-term risk about the trend of electricity, gas, and carbon prices is represented using an exponential formula which uses price forecasts in year zero $\left(P_{0}\right)$, year ten $\left(P_{10}\right)$ and 
year twenty $\left(P_{20}\right) .^{20}$ The prices forecasts $P_{0}, P_{10}$, and $P_{20}$ are independent random variables which are uniformly distributed around the expected value.

Table 5: Electricity, gas, and carbon price stochastic evolution distribution parameters

\begin{tabular}{|c|c|c|c|c|c|c|}
\hline Expected value & \multicolumn{2}{|c|}{$\begin{array}{l}\text { Electricity Price } \\
\text { (p/KWh) }\end{array}$} & \multicolumn{2}{|c|}{$\begin{array}{l}\text { Gas Price } \\
\text { (p/therm) }\end{array}$} & \multicolumn{2}{|c|}{$\begin{array}{l}\text { Carbon Price } \\
(£ / t C)\end{array}$} \\
\hline Projected Price in yr. $0\left(P_{0}\right)$ & \multicolumn{2}{|c|}{4} & \multicolumn{2}{|c|}{30} & \multicolumn{2}{|c|}{50} \\
\hline Projected Price in yr. $10\left(P_{10}\right)$ & \multicolumn{2}{|c|}{6} & \multicolumn{2}{|c|}{45} & \multicolumn{2}{|c|}{75} \\
\hline Projected Price in yr. $20\left(P_{20}\right)$ & \multicolumn{2}{|c|}{7.5} & \multicolumn{2}{|c|}{60} & \multicolumn{2}{|c|}{100} \\
\hline $\begin{array}{l}\text { Uniform Distributions } \\
\text { Bounds }\end{array}$ & $\begin{array}{l}\text { Lower } \\
\text { bound }\end{array}$ & $\begin{array}{l}\text { Upper } \\
\text { bound }\end{array}$ & $\begin{array}{l}\text { Lower } \\
\text { bound }\end{array}$ & $\begin{array}{l}\text { Upper } \\
\text { bound }\end{array}$ & $\begin{array}{l}\text { Lower } \\
\text { bound }\end{array}$ & $\begin{array}{l}\text { Upper } \\
\text { bound }\end{array}$ \\
\hline Distribution of $P_{0}$ & 3.6 & 4.4 & 24 & 36 & 25 & 75 \\
\hline Distribution of $P_{10}-P_{0}$ & 0 & 3 & 0 & 30 & 0 & 50 \\
\hline Distribution of $P_{20}-P_{10}$ & 0 & 3 & 0 & 30 & 0 & 50 \\
\hline \multirow[t]{2}{*}{ Annual Price Volatility } & \multicolumn{6}{|c|}{$\begin{array}{l}\text { Uniform distribution of Price growth spread around } \\
\text { projected value }\end{array}$} \\
\hline & \multicolumn{2}{|c|}{$20 \%$} & \multicolumn{2}{|c|}{$20 \%$} & \multicolumn{2}{|c|}{$30 \%$} \\
\hline
\end{tabular}

Table 5 shows the expected value of electricity, gas, and carbon prices in years zero, ten and twenty along with the upper and lower bounds of the uniform distribution. The expected parameters are based on judgement informed by historical data and British and US forecasts (DTI, 2004 and DOE, 2004). The lower trajectory represents the most optimistic scenario in which prices remain stable, while the upper bound corresponds to a 'worst case' 'gas shock' scenario in which prices would more than double over forty years.

Random trajectories for the electricity, gas, and carbon prices are drawn for a series of Monte Carlo simulations. The continuum of possible long-term price trajectories of electricity prices is represented on Figure 1, together with the upper and lower bounds of the projected price. The long-term gas and carbon price trajectories are presented in the Appendix.

In addition, the stochastic process incorporates a shorter-run (annual) risk component, corresponding to the yearly deviations form the long-run trend. Gas and electricity are assumed to be bought and sold on spot markets, or through contracts indexed on the spot market price, thereby subjecting generators to annual price volatility. ${ }^{21}$ The 'realised price' therefore embeds some additional yearly uncertainty in the underlying 'projected price'. This

${ }^{20}$ The mathematical formulation of this "projected price" is $P(t)=P_{20}-\alpha \cdot e^{-\beta t}$, where $\alpha=P_{20}-P_{0}$, and $\beta=-\frac{1}{10} \cdot \ln \left(\frac{P_{20}-P_{10}}{P_{20}-P_{0}}\right)$.

${ }^{21}$ The model does not account for long-term fixed-price gas procurement or electricity sales contracts. Such contracts are rare in current liberalised markets, and would affect the nuclear option value in two opposite ways. First, by reducing the fuel price risk for gas generators, fixed-price gas procurement contracts reduce the hedging value associated with technologies such as nuclear that are not exposed to gas price fluctuations. On the other hand, long term power purchase agreements under which the Finnish nuclear plant is now being constructed reduce nuclear plant profit uncertainty and thereby increase nuclear's hedging value. 
yearly uncertainty might, for instance, occur because of milder or colder weather, or from unexpected events (e.g. extended unavailability of a power station or disruption to fuel supplies). This annual risk is modelled by multiplying the yearly price growth generated by the long run trend with a uniformly distributed independent random variable with upper and lower bounds of 0.8 and 1.2 for electricity and gas prices, and 0.7 and 1.3 for the carbon price (Li and Flynn, 2004).

\subsubsection{Investor technology choice}

Following the work from Ford (1999 and 2001) and Olsina et al. (2005) on investor behaviour in electricity markets, investors are modelled as having a somewhat limited knowledge about future electricity, gas, and carbon prices. In our model, we assume that investors have neither perfect foresight nor perfect information. They form estimates of the future profitability (future cash flows) of the two different technologies at each decision point based on historical electricity, fuel, and carbon price data. Investors choose to invest in nuclear if the expected cash flow of a CCGT plant using price estimates based on the average trend of the last 5 years is lower than a certain threshold $P^{*}$. This '5-year cash flow threshold' $P^{*}$ is chosen in order to maximise the expected NPV of the investment program by using a dynamic optimisation program. $^{22}$

The use of such a 'backward-looking' technology choice rule ignores any meanreversion effects but appears justified by the behaviour of investors in liberalised electricity markets. For example in the U.S. in 1999-2000 investors, based on their recent experience saw nothing but cheap natural gas prices and started building CCGT plants. All of that additional demand came on stream as gas prices rose sharply and led to the financial collapse of many investors.

The sensitivity analysis presented in the Appendix shows that the nuclear option value is robust to small optimisation errors around the optimal 'profitability threshold' $P^{*}$. Our approach avoids the curse of dimensionality of dynamic programming that would have otherwise rendered our model intractable with a standard perfect foresight option valuation approach, given the complexity of the model (in particular the embedded option not to operate an already built CCGT at a loss and the correlation between the three different stochastic price processes).

\subsection{Results: nuclear option value}

Monte Carlo simulation yields a probability distribution for the nuclear option NPV, calculated as the difference between the NPV distributions with and without the nuclear option. The nuclear option affects the risk-return profile of the company investment plan in two ways:

\footnotetext{
${ }^{22}$ The stochastic optimisation program @RISK was used to derive the optimal profitability thresholds. The code is available from the corresponding author upon request.
} 
- First, comparing the shape of the investment plan NPV distribution with and without the nuclear option, the likelihood of low NPVs is much less when the company can choose nuclear if the spark spread is low. ${ }^{23}$ This is represented graphically on the right hand side of Figure 2 by the shift downward of the lower left hand tail of the 5-plant NPV distribution: in the scenarios where the spark spread is low, a nuclear plant has a higher NPV than a CCGT, while the reverse is true when the spark spread is high.

- Second, high NPVs are more likely when the company has the choice between two technologies, as shown by the shift upward of the right hand side tail of the five plant NPV distribution.

Figure 2: NPV distributions for single CCGT and Nuclear plants and for the 5-plant investment plan with and w/o nuclear option ( $10 \%$ discount rate), zero correlation between electricity, gas, and carbon prices (Emillion).
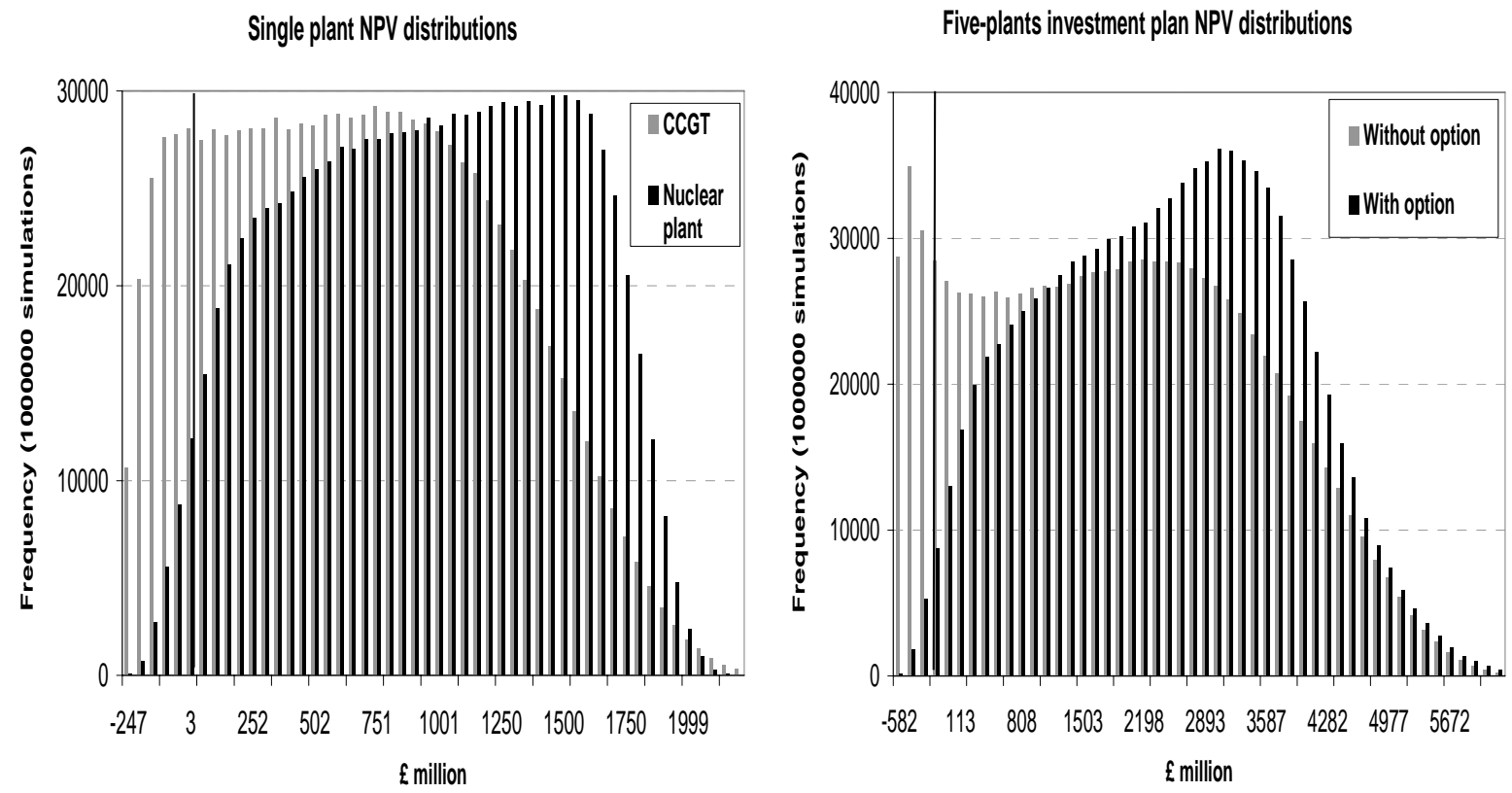

When there is no correlation between electricity, gas, and carbon prices, the expected value of the nuclear option distribution for the five-plant investment plan with a $10 \%$ discount rate is $£ 181$ million or $£ 36$ million per plant (i.e. $£ 36 / \mathrm{kW}$ capacity), around $9 \%$ of the expected NPV of the nuclear plant itself ( $£ 418$ million). It stands at respectively $£ 524$ million and $£ 1551$ million for $8 \%$ and 5\% discount rates, reflecting the large influence of the cost of capital on the relative profitability of a nuclear and CCGT plants highlighted in the previous section. However, the degree of correlation between electricity, gas, and carbon prices has a dramatic impact on this nuclear option value, as we shall see.

Two factors affect the option value: the ability to choose, and the hedging or diversification value of a more diverse portfolio for the company. The distributions shown in

\footnotetext{
${ }^{23}$ The spark spread is the difference between the electricity price and the cost of the gas needed to generate the unit of electricity, and contributes to non-fuel costs. It is quoted in price reporting services such as Platts.
} 
the left hand-side of Figure 2 show that a single nuclear investment is intrinsically less risky than a single CCGT investment. In addition, there is the portfolio risk-reducing effect when two assets have non-perfectly correlated costs. This has been extensively studied by Awerbuch and Berger (2003) and Awerbuch and Sauter (2005) for electricity technology diversification.

\subsection{The impact of gas and electricity price correlation}

The previous estimate of the option value relies critically on the assumption that gas, carbon and electricity prices are uncorrelated. In reality these prices exhibit quite a strong correlation, reflecting the complex interaction between electricity, gas, and carbon markets. This arises because gas-fired plant frequently sets the price of electricity, and because generators can arbitrage between electricity production or reselling the contracted gas.

Daily quarter-ahead forward prices for base-load electricity and gas in the UK market from 2001 to August 2005 exhibit a correlation factor of 89\%. The correlation between electricity and carbon prices from the start of trading in October 2004 until September 2005 stands at $73 \% .{ }^{24}$ Clearly such high correlations cannot be ignored. The model is therefore modified to assume that the correlations between electricity, gas and carbon prices are identical and constant over time in the stochastic price processes described in section 3.2.1.

Figure 3: Relation between the expected NPV of the 5-plant nuclear option and the degree of correlation between electricity, gas, and carbon prices (Emillion)

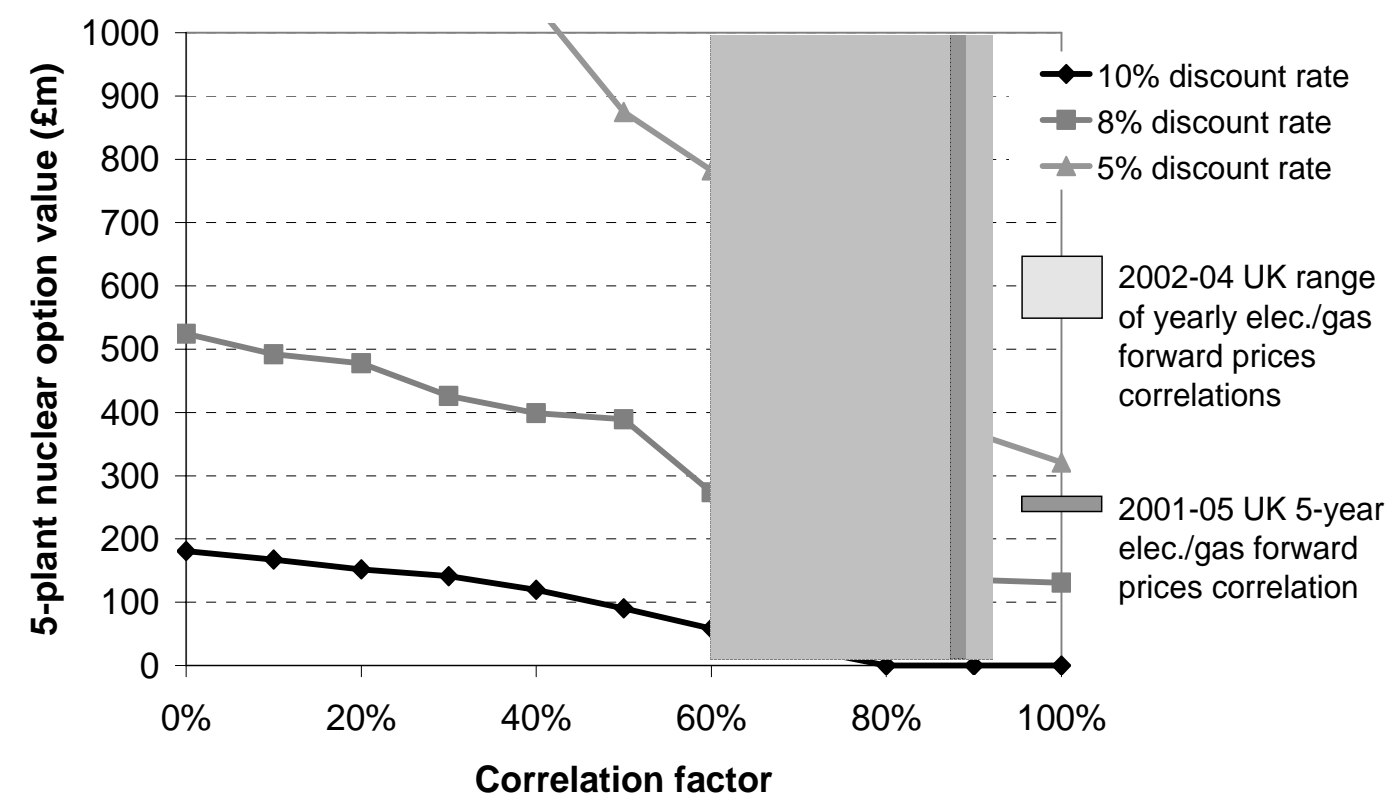

\footnotetext{
${ }^{24}$ The reference of the daily quarter-ahead data on electricity base-load prices in the UK market from Platts is AAFPP00, and the reference for the daily quarter-ahead UK NBP gas prices from Platts is AACPV00, while the
} 
The degree of correlation has a dramatic effect on the nuclear option value (Figure 3). In the case of a $10 \%$ discount rate, the expected NPV of the nuclear option is reduced by $85 \%$ for a $70 \%$ correlation (to $£ 28$ million, or $£ 5.6$ million per plant). For discount rates of $8 \%$ and $5 \%$, the expected NPV of the nuclear option is reduced respectively by 59\% (to $£ 213$ million), and by 55\% (to $£ 698$ million) for a 70\% correlation.

The intuition is that a higher correlation reduces both the intrinsic riskiness of CCGT investment (as electricity prices rise when gas and/or carbon prices rise), and the portfolio diversification benefits of having two assets with non-perfectly correlated returns.

Figure 4 shows the effect of a 70\% correlation on the distribution of the NPV of each investment on the right-hand side, and on the 5-plant investment plan with and without the nuclear option on the left-hand side. The right-hand side shows that the spread of the CCGT distribution, as well as the likelihood of a negative NPV, falls to lower levels than for a nuclear investment. ${ }^{25}$

Figure 4: NPV distributions of single CCGT and Nuclear plants and for the 5-plant investment plan with and w/o nuclear option ( $10 \%$ discount rate), $70 \%$ correlation between electricity, gas, and carbon prices (Emillion) - c.f. Figure 2.

Single plant NPV distributions

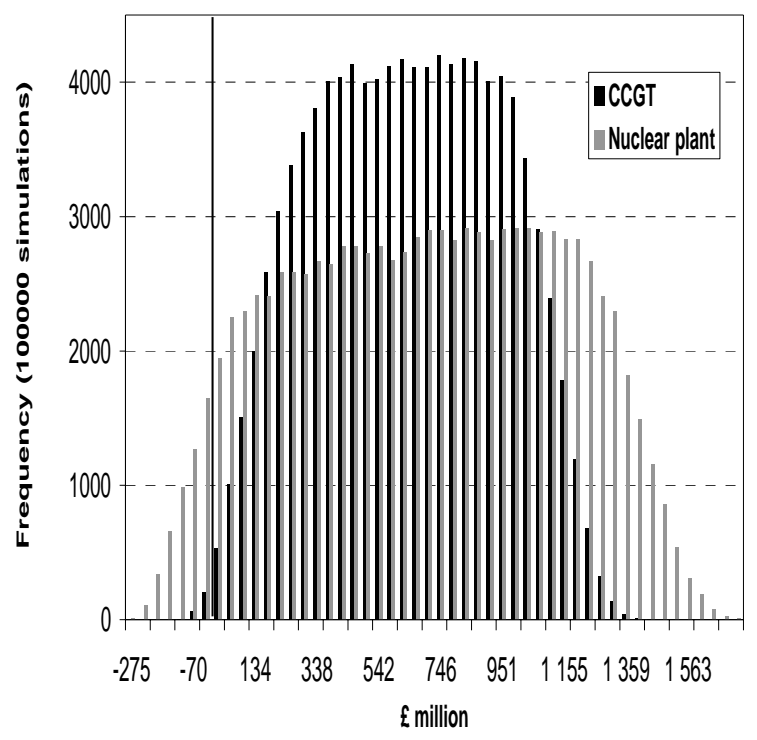

Five-plants investment plan NPV distributions

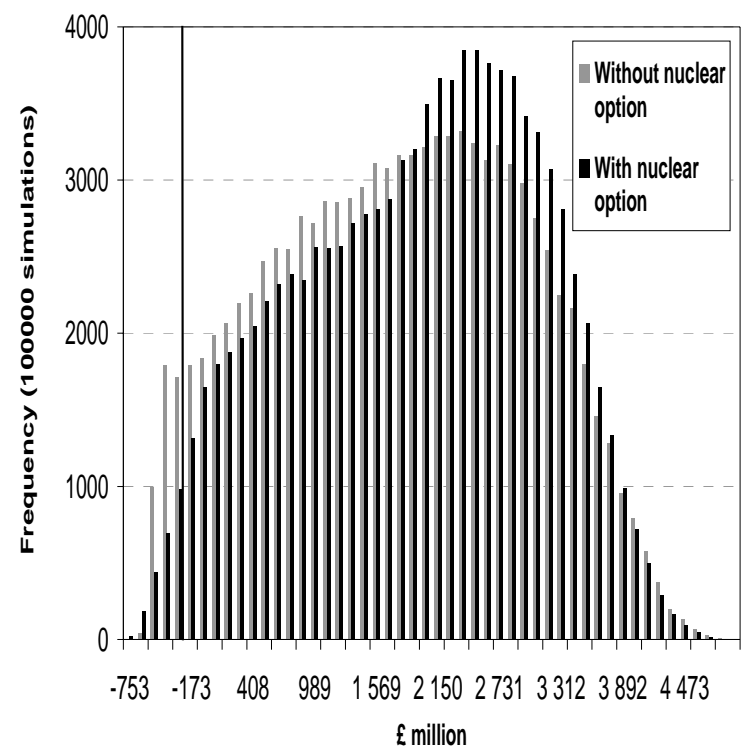

The correlation between the main cost (gas and carbon prices) and revenue (electricity price) drivers of the CCGT investment reduces its intrinsic riskiness to a lower level than a nuclear plant, which is only subject to revenue (electricity price) risk. The more correlated the costs and revenues of the CCGT plant, the narrower is its NPV distribution, while the NPV distribution of the nuclear plant remains unchanged. This implies that a greater degree of

carbon prices data are from the EEX CO2 index. These results are coherent with Awerbuch and Berger (2003) correlation estimates. 
correlation between electricity, gas and carbon prices reduces the potential intrinsic risk reduction value for the company, and thereby significantly reduces the nuclear option value.

In addition, higher correlations also reduce the portfolio diversification effect for two reasons. First, as the volatility of the spark spread falls, the nuclear plant investment is chosen less often, so that the company has a greater proportion of CCGT plants. Second, as the volatility of the spark spread falls, the correlation between the returns of a CCGT plant and a nuclear plant increases, so that the value of the portfolio risk-reduction effect associated with a mix of the two technologies falls. For commercial discount rates (10\%), a CCGT investment is more profitable than a nuclear plant, so that this portfolio diversification effect is the dominant source of risk mitigation. This explains why the nuclear 'option value' is relatively more affected by correlation for high discount rates.

\subsection{Policy implications}

The conclusion of our model is that there is little private company value in retaining the option to choose between nuclear and CCGT technologies in future in liberalised European electricity markets, which exhibit a strong correlation between electricity, gas and carbon prices. This result appears consistent with the observation that most new power plants built in liberalised electricity markets since the 1990s have been gas-fired power stations.

The increase in the share of gas in the electricity fuel-mix has raised concerns among policy-makers about the growing gas-import dependency and the resulting increased foreign exchange rate exposure to gas price fluctuations. ${ }^{26}$ The literature investigating the optimal national degree of generation diversity (Awerbuch and Berger 2003, Stirling 2001) argues that a diverse fuel and technology-mix has two macroeconomic benefits. First, non-fossil fuel technologies reduce fossil fuel price risk and help avoid costly economic losses. Awerbuch and Sauter (2005) assert that the observed negative relationship between fossil fuel price changes and economic activity justifies subsidies for renewable energy, nuclear power and demand side management. Second, a diverse system is intrinsically more robust to supply shocks and therefore fuel-mix diversity benefits security of supply (Stirling, 2001).

One critical issue to the long-term sustainability of liberalised electricity markets lies in their ability to deliver adequate and timely investment signals to ensure security of supply. In particular, there are concerns that a liberalised industry would fail to provide appropriate incentives for diversification, to deliver the macro-economically optimal fuel-mix diversity. Ideally, micro-economic investment incentives should reflect the macro-economic value of a diverse fuel-mix. Our results and the observed investment patterns in liberalised electricity markets over the last decade lend some support to this fear. One possible way in which private and social objectives might be reconciled is through the portfolio decisions of final consumers, who would value assets that had high returns in cases of high electricity prices

\footnotetext{
${ }^{25}$ The detailed statistics of the probability distributions of Figures 2 and 4 are presented in the Appendix.

${ }^{26}$ For instance, the UK gas import dependency is forecast to rise from $50 \%$ in 2004 to more than $80 \%$ by 2020 (JESS, 2003).
} 
(i.e. high gas and/or carbon prices). The Finnish 2004 nuclear plant investment suggests that this can be important.

Further research is therefore needed to assess both the macroeconomic optimal technology and fuel-mix degree of diversity, and private investors' diversification incentives in electricity markets. If the case for a market failure in the form of unpriced fuel-mix diversity externalities providing economics and security of supply benefits were to be demonstrated, it might justify intervention in electricity markets to subsidise non fossil-fuel technologies beyond the present carbon price.

\section{CONCLUSION}

Despite recent revived interest in nuclear power, the prospects for merchant nuclear investment in liberalised industries without government support do not seem promising. The reason is relatively simple: quite apart from overcoming any regulatory and public opinion difficulties, the economic risks of nuclear power have been adversely affected by liberalisation. High capital cost, uncertain construction cost, potential construction and licensing delays, and economies of scale are the main features that make nuclear power technology unattractive to private investors in liberalised electricity markets. Couching the debate over the economics of nuclear power in terms of the expected levelised cost fails to capture these concerns adequately. Recent cost estimates reveal both the large underlying nuclear cost uncertainties and different interpretations of the impact of liberalisation on the cost of finance and hence investment choices.

The second part of the paper examined the claim that nuclear and non-fossil fuel technologies have a private 'option value' not captured by traditional valuation approaches. This is modelled in a 5-plant company investment plan capturing the main technologyspecific characteristics of nuclear and CCGT plant. The model uses stochastic optimisation to estimate the option value of being able to choose between nuclear and CCGT technologies in the future. We find, for the higher discount rates that could be expected for most private new nuclear build (10\% real), that the nuclear option value represents $9 \%$ of the expected net present value of a nuclear plant investment when there is no correlation between electricity, gas, and carbon prices, but that this positive attribute falls away sharply with increasing correlation between these prices. Such correlations are well established in most liberalised markets and we demonstrate this for the UK market.

These results imply that there is little private value in retaining the nuclear option in current electricity markets, with high discount rates and strong correlations between electricity, gas and carbon prices. Our modelling does not conclude that fuel mix diversity via nuclear power is of no value in contexts where markets have been liberalised. We simply conclude that there is little or no value for utilities or merchant generators preserving such an option. The UK government clearly accepts that there is a social or consumer value in 'keeping the nuclear option open' as this has formed a part of UK government policy since the Energy White Paper of 2003 (Stenzel, 2003). The Finnish experience is showing us that if 
well informed and strategic and users of electricity have (via long-term contracts) a strong influence on market decisions, then nuclear new build can be a realistic option in liberalised markets.

However, given that the bulk of electricity consumers (even industrial consumers) are not well-informed about the electricity market, and seem reluctant to sign contracts for longer than 3 years, as well as attaching minor importance to hedging electricity price risks, our modelling would appear to indicate that there may be a case for policy intervention to ensure fuel mix diversity in fully liberalised markets, such as those operating in England and Wales, providing of course that there is clear evidence of a costly market failure that can be cost effectively remedied by such intervention. It can be appropriate for government to insure the public against evident risks when it is clear that the public is poorly equipped to address them. In time consumers will surely become more sophisticated and we note recent moves to offer even domestic retail consumers long-term price-capped, albeit premium, rates. In the Nordic electricity market, von der Fehr et al. (2005) note that there was a general move from variable-price contracts to fixed-price contracts in the wake of the price increase during the winter of 2003. More than $60 \%$ of the manufacturing industry, $30 \%$ of the service industry, and $20 \%$ of the households were purchasing their electricity through fixed-price contracts in 2004. Adequately long-term fixed price contracts could favour the nuclear option but there are few examples of very long-term consumer contracts outside the Finnish example. Perhaps in the future, therefore, all liberalised markets will follow in the steps of the Finnish experience, but at present this is far from clear.

\section{APPENDIX}

\section{Projected and realised gas and carbon prices}

Figure 5: Projected and realised gas and carbon prices 
Projected and realised gas prices ( $p /$ therm)

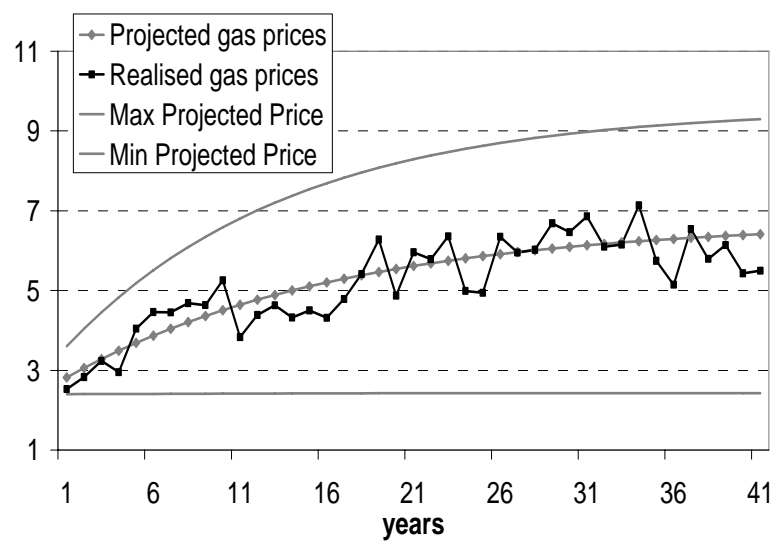

Projected and Realised Carbon Price ( $£ / t C)$

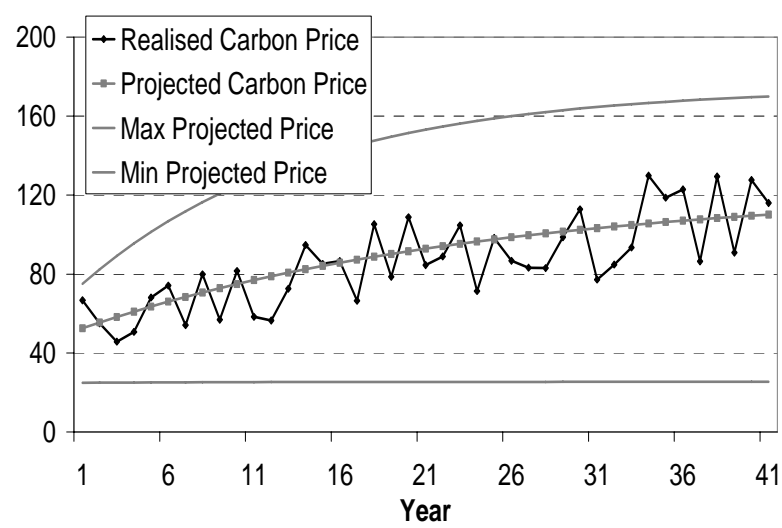

\section{NPV distributions statistics}

Table 6: Individual CCGT and Nuclear plant NPV distributions statistics for various degrees of electricity, gas and carbon prices correlation (Emillion)

\begin{tabular}{|lcccccc|}
\hline & \multicolumn{3}{c}{ CCGT } & \multicolumn{4}{c|}{ Nuclear } \\
\hline & \multicolumn{1}{c}{ Degree of correlation between electricity and gas prices } \\
\hline & $\mathbf{0 \%}$ & $\mathbf{4 0 \%}$ & $\mathbf{1 0 0 \%}$ & $\mathbf{0 \%}$ & $\mathbf{4 0 \%}$ & $\mathbf{1 0 0 \%}$ \\
\hline Mean & 686 & 658 & 657 & 722 & 723 & 722 \\
\hline $\begin{array}{l}\text { Standard } \\
\text { Deviation }\end{array}$ & 549 & 418 & 220 & 452 & 453 & 452 \\
\hline Minimum & -272 & -244 & 132 & -318 & -306 & -314 \\
\hline Maximum & 2490 & 1800 & 1227 & 1803 & 1803 & 1760 \\
\hline $\begin{array}{l}\text { Range } \\
\text { Width }\end{array}$ & 2762 & 2043 & 1094 & 2122 & 2109 & 2074 \\
\hline
\end{tabular}

Table 7 - Five-plants investment plan NPV distribution statistics with and w/o nuclear option, for various degrees of electricity, gas and carbon prices correlation (£million)

\begin{tabular}{|lccccccccc|}
\hline & \multicolumn{2}{c}{$\begin{array}{c}\text { Total (5plants) NPV } \\
\text { with option }\end{array}$} & \multicolumn{2}{c}{$\begin{array}{c}\text { Total (5plants) NPV } \\
\text { w/o option }\end{array}$} & \multicolumn{3}{c|}{ Option value } \\
\hline $\begin{array}{l}\text { Correlation btw. } \\
\text { Elect.\& gas prices }\end{array}$ & $\mathbf{0 \%}$ & $\mathbf{4 0 \%}$ & $\mathbf{1 0 0 \%}$ & $\mathbf{0 \%}$ & $\mathbf{4 0 \%}$ & $\mathbf{1 0 0 \%}$ & $\mathbf{0 \%}$ & $\mathbf{4 0 \%}$ & $\mathbf{1 0 0 \%}$ \\
\hline Mean & 2090 & 1943 & 1822 & 1910 & 1791 & 1811 & 180 & 153 & 12 \\
\hline $\begin{array}{l}\text { Standard } \\
\text { Deviation }\end{array}$ & 1306 & 1140 & 1001 & 1567 & 1194 & 617 & 610 & 411 & 570 \\
\hline Range Width & 7675 & 5807 & 4940 & 7487 & 5610 & 3260 & 4180 & 3338 & 3248 \\
\hline
\end{tabular}

3. Robustness of the option value to investors' decision rule

Figure 6: Sensitivity analysis of investors' optimal profit threshold impact on the 5-plant nuclear option value $(\mathrm{Em})$ 


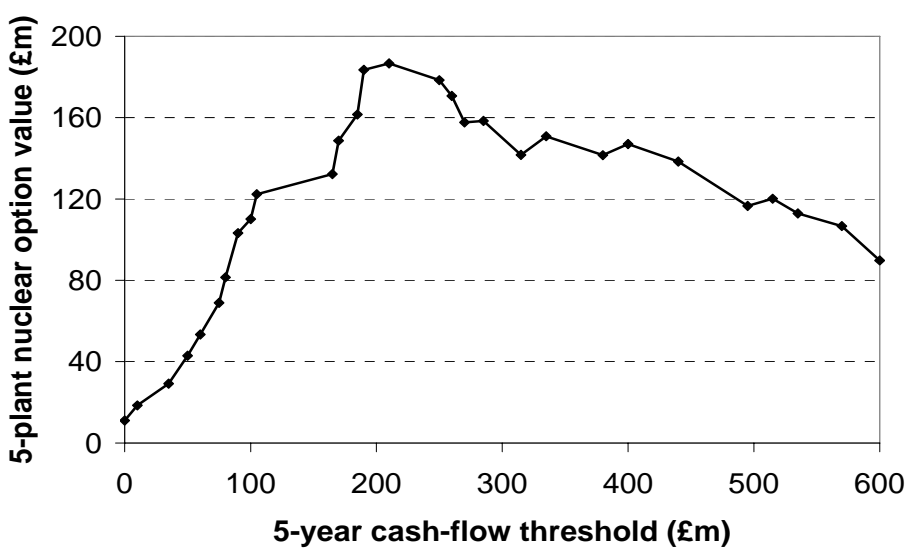

Figure 6 shows that the nuclear option value is robust to small errors of the optimisation program around the optimal threshold (217£/KWh in this case): the nuclear option value varies less than $2 \%$ over the range [200; 250] spread around the optimal 6-year cash flow threshold.

\section{Discount rate}

Figure 7 shows that as the discount rate is lowered below 10\%, a nuclear plant investment becomes much more profitable than a CCGT investment, and therefore the nuclear option value increases. Moreover, it shows that the impact of correlation between electricity, gas, and carbon prices is relatively greater for high discount rates.

Figure 7: Discount rate impact on the 5-plant nuclear option value $(\mathrm{Em})$

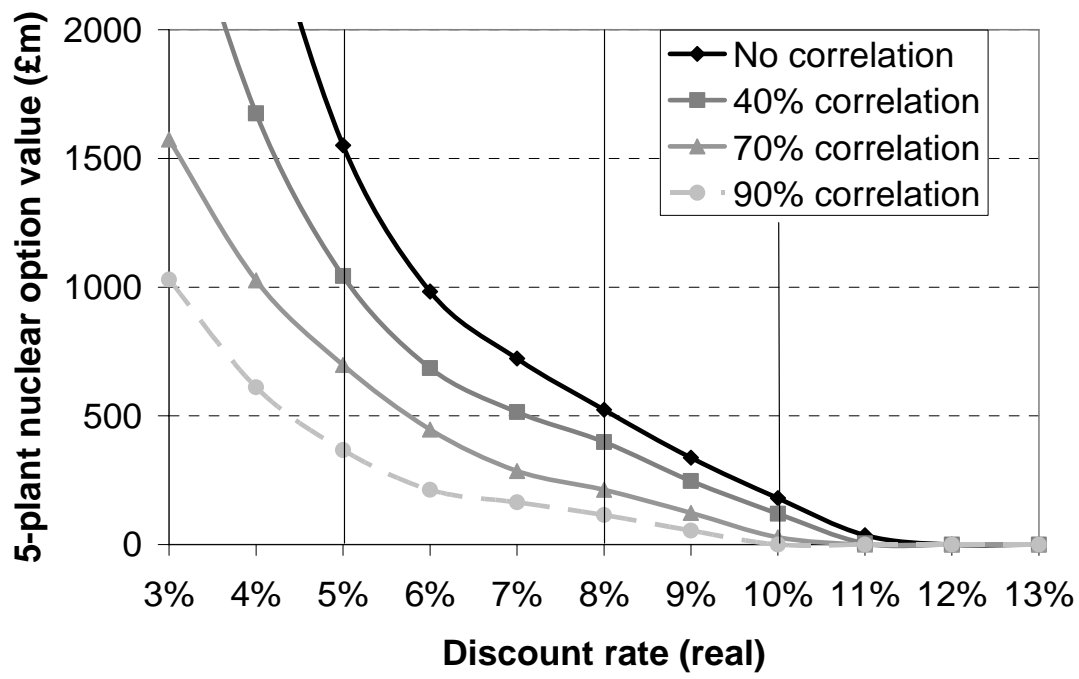

\section{Construction time and overnight capital cost}

Figures 8 and 9 show that the impact of varying the construction time and the overnight capital cost on the 5-plant investment plan option value is much larger for high discount rates. 
Figure 8: Impact of the construction time on the 5-plant nuclear option value ( $\mathrm{Em})$
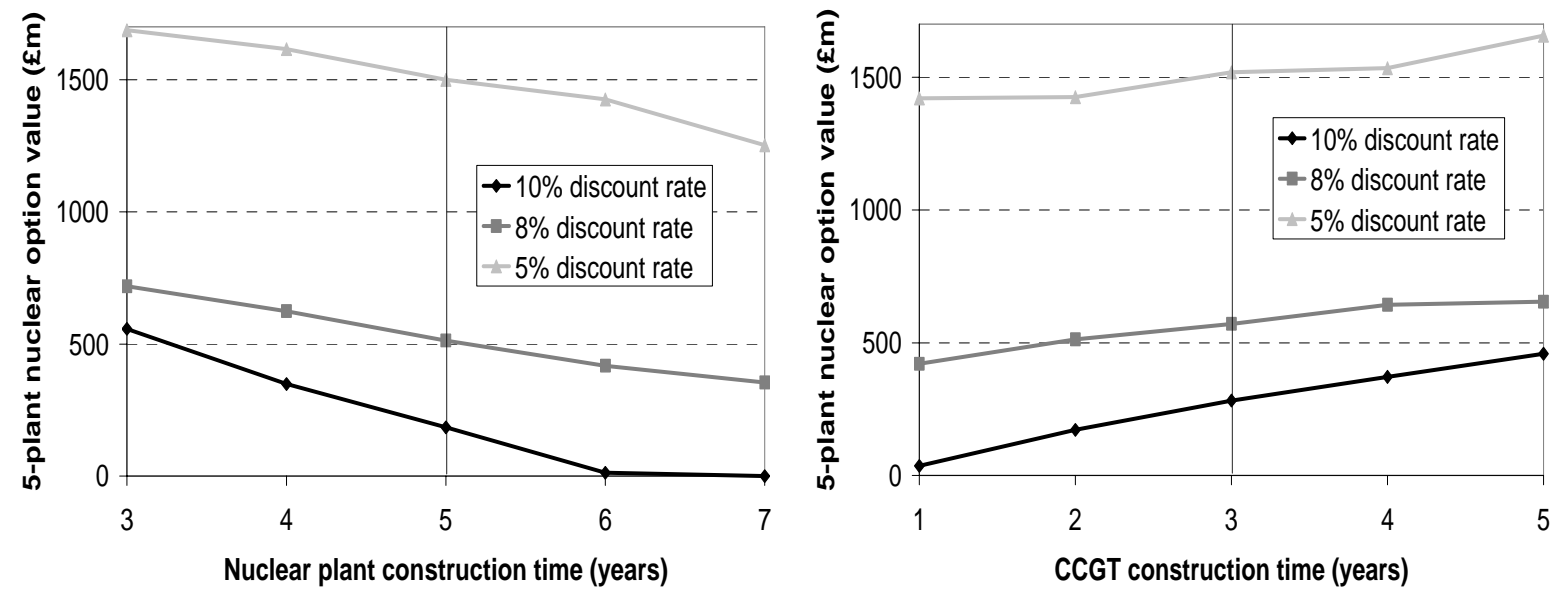

Figure 9: Impact of the overnight capital costs on the 5-plant nuclear option value (£m)

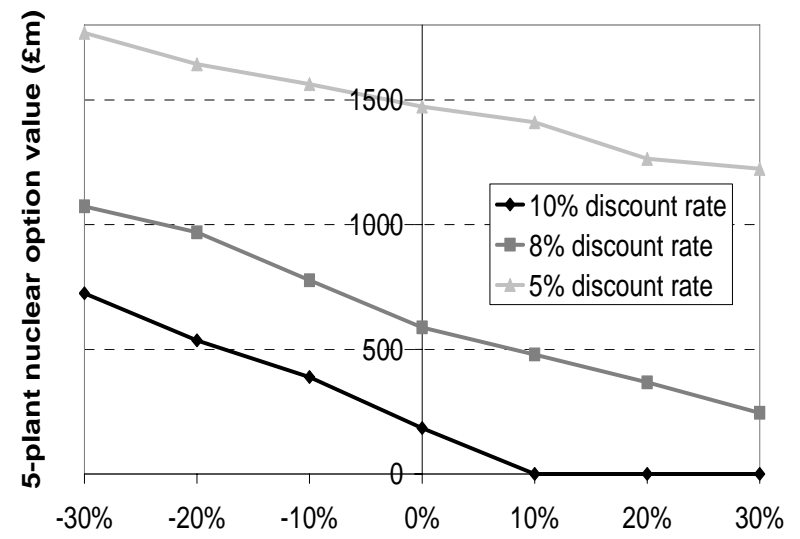

Percentage change in nuclear capital costs

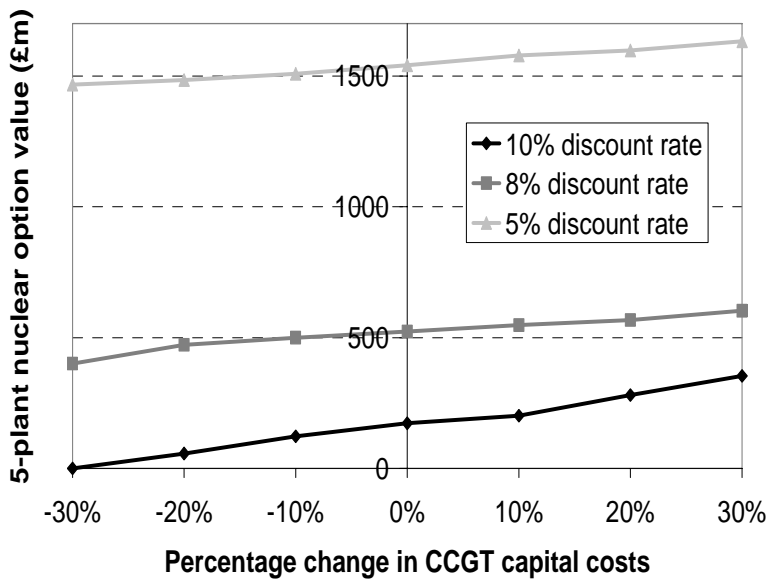

Percentage change in CCGT capital costs

6. Cost parameters: Nuclear fuel cost, nuclear waste fee, and $O \& M$ costs

Figure 10: Impact of the nuclear fuel cost and waste fee on the 5-plant option value ( $\mathrm{Em})$ 

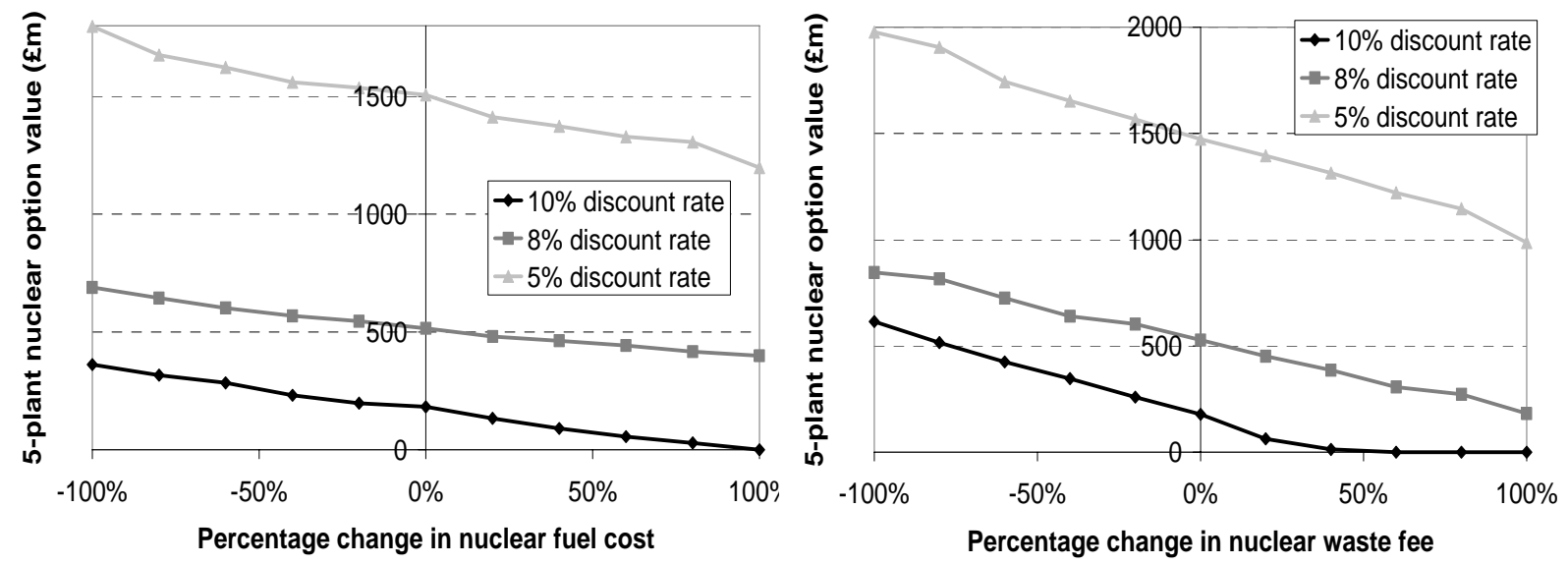

Figure 11: Impact of the O\&M fixed costs on the 5-plant nuclear option value ( $\mathrm{Em})$
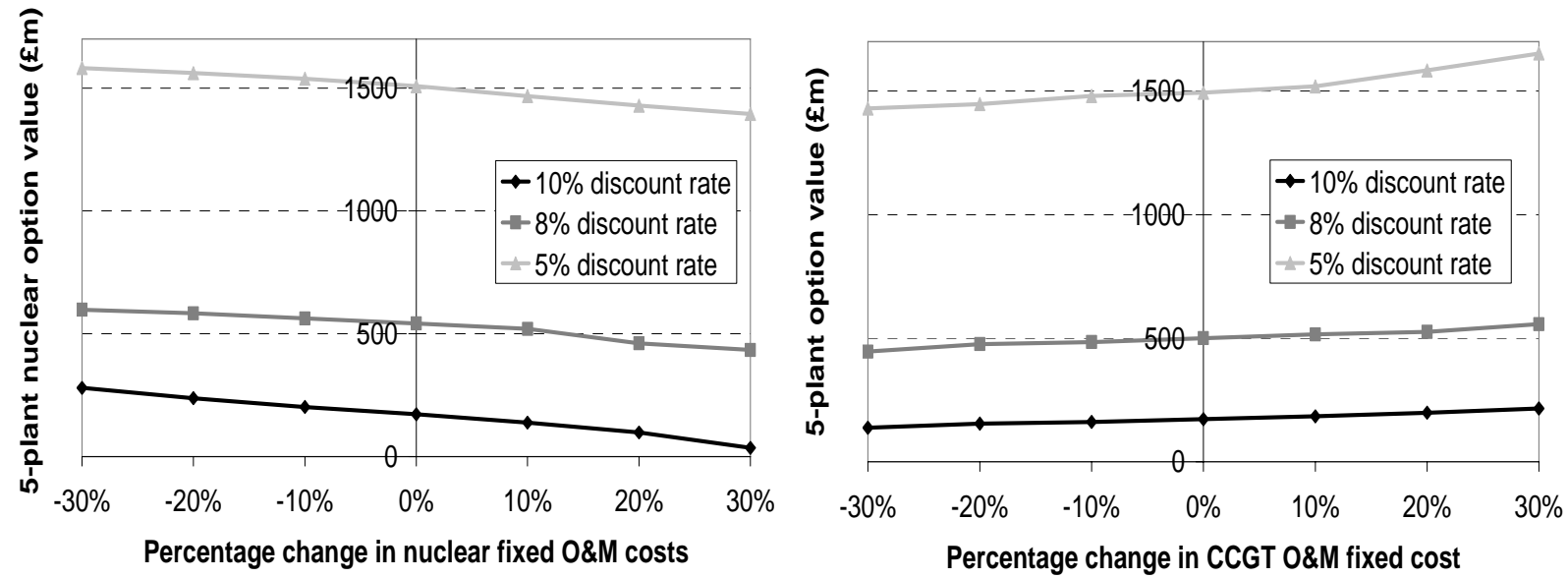

7. Technical parameters: availability factor and heat rate

Figure 12: Impact of the plant technical availability on the 5-plant nuclear option value ( $\mathrm{Em})$ 

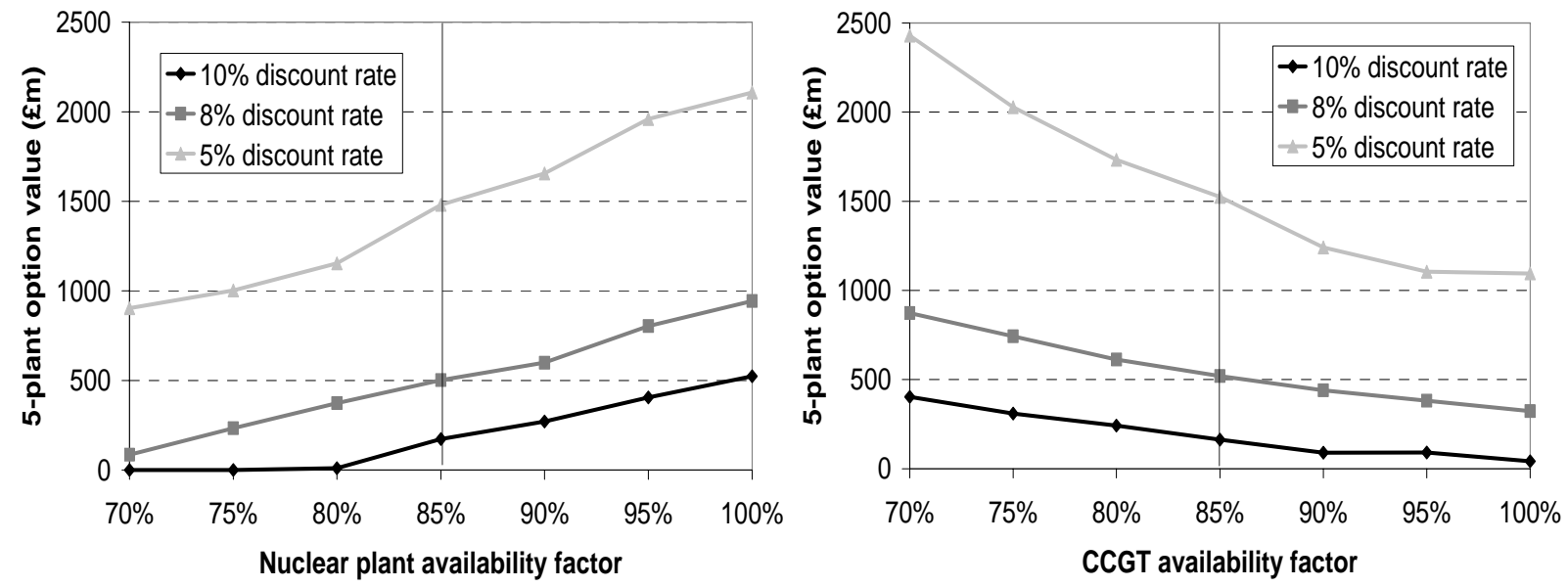

Figure 13: Impact of the plant efficiency on the 5-plant nuclear option value (£m)
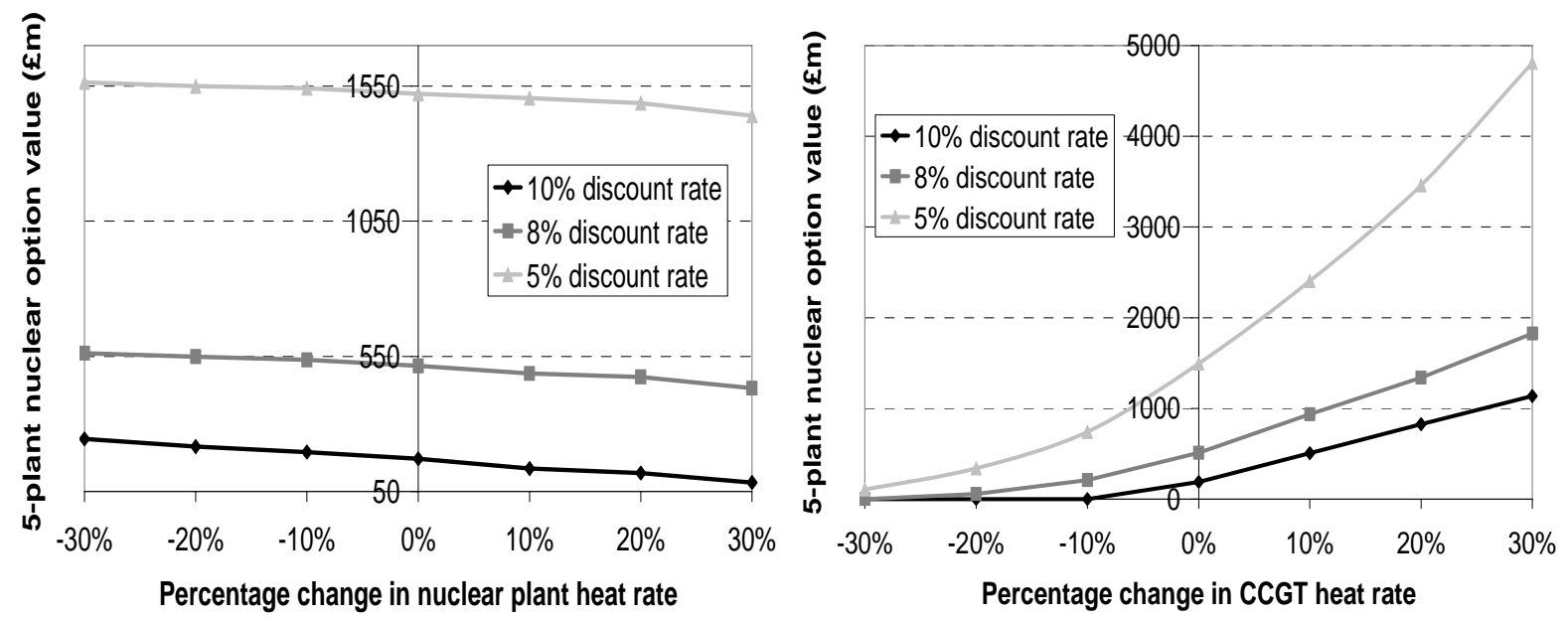

\section{REFERENCES}

Ampere (2000), "Rapport de la Commission pour l'Analyse des Modes de Production de l’Électricité et le Redéploiement des Énergies (AMPERE)", Bruxelles.

Awerbuch, S. and R. Sauter (2005), "Exploiting the Oil-GDP Effect to Support Renewables Deployment”, SPRU Electronic Working Paper Series, Paper No. 129, January 2005.

Awerbuch, S. and M. Berger (2003), "Energy Security and Diversity in the EU: A Mean-Variance Portfolio Approach,” IEA Research Paper, Paris, February 2003.

Averch, H. and L. Jonhnson (1962), "Behavior of the Firm under regulatory constraint,” American Economic Review 52: 1053-69.

Bar-Ilan A., and W. Strange (1996), “Investment lags,” American Economic Review, 86: 611-622. Cox, J., S. Ross, and M. Rubinstein (1979), “Option Pricing: A Simplified Approach,” Journal of Financial Economics, 7, 263-384. 
Department of Energy (2004), Energy Information Administration (EIA), “Annual Energy Outlook”, DOE/EIA-0383(2004), January 2004.

Deutch J., E. Moniz, S. Ansolabehere, M. Driscoll, P. Gray, J. Holdren, P. Joskow, R. Lester, and N. Todreas (2003), "The Future Of Nuclear Power", an MIT Interdisciplinary Study, http://web.mit.edu/nuclearpower/.

Department of Trade and Industry (2004), Quarterly Energy Prices (Dec 2004).

Dideme (2003), "Coûts de référence de la production électrique", December 2003, DGEMP-DIDEME, Paris.

Dixit, A. and. R. Pindyck (1994), “Investment Under Uncertainty”, Princeton University Press.

Ford, A. (1999), "Cycles in competitive electricity markets: a simulation study of the western United States,” Energy Policy, 27: 637

Ford, A. (2001), "Waiting for the Boom: A Simulation Study of Plant Construction in California," Energy Policy, 29: 847-869.

Frayer, J. and N. Uludere (2001), "What Is It Worth? Application of Real Options Theory to the Valuation of Generation Assets,” The Electricity Journal 14(oct): 40-51.

Geman H. (2005), “Commodities and Commodity Derivatives - Modelling and Pricing For Agriculturals, Metals And Energy,”John Wiley and Sons LTD.

Gollier C., D. Proult, F. Thais and G. Walgenwitz (2005), "Choice of nuclear power investments under price uncertainty: Valuing modularity,” Energy Economics 27(4): 667-685.

International Energy Agency (2005), “Projected costs of generating electricity, 2005 update”, OECD publication, Paris.

International Energy Agency \& Nuclear Energy Agency, (2000), 'Reduction of Capital Costs of nuclear power plants', OECD publication, Paris.

JESS (2003), Joint Energy Security of Supply Working Group DTI/OFGEM, Second report.

Lester R. and M. McCabe (1993), “The effect of industrial structure on learning by doing in nuclear power plant operation”, RAND Journal of Economics 24 (3): 418-438.

Li, Y., and P. Flynn (2004), “Deregulated power prices: comparison of volatility,” Energy Policy 32: 1591-1601.

Ludwigson J., Rusco F., Walls, D. (2004),"Buying an option to build: regulatory uncertainty and the development of new electricity generation”, IAEE Newsletter, Second Quarter 2004, p.17-21.

Murto, P., and Nese, G.(2002), "Input price risk and optimal timing of energy investment: choice between fossil- and biofuels", Working Paper No. 25/02, Institute for Research in Economics and Business Administration, Bergen, May 2002.

NEA (2000), Nuclear Energy Agency, "Reduction of Capital Costs of Nuclear Power Plants".

Nuclear Energy Institute (2004), “U.S. Nuclear Power Plant Capacity and Capacity Factors,” available on NEI's website http://www.nei.org/.

Newbery D., and R. Green (1996), "Regulation, public ownership, and privatisation of the English electricity industry”, in R.J. Gilbert and E.P. Kahn (eds), International Comparisons of Electricity regulation, Cambridge university Press, p. 25-81.

Nuttall W. J. (2004), "Nuclear Renaissance: Technologies and Policies for the Future of Nuclear Power”, Bristol: Institute of Physics Publishing.

Olsina, F., F. Garces, and H.-J. Haubrich (2005), "Modelling long-term dynamics of electricity markets," Energy Policy, in Press.

Pindyck, R. (1993), “Investments of uncertain cost,” Journal of Financial Economics 34: 53-76. 
Rothwell, G., Energy Path Corporation and Sandia Laboratories (2005), “NP2010 Texas Gulf Coast feasibility study, final report”, prepared by the Texas Institute for the Advancement of Chemical Technology, 28 February 2005, www.nrgpath.com.

Royal Academy of Engineering (2004), “The Cost of Generating Electricity”, a study carried out by PB Power for the Royal Academy of Engineering, London.

Scully Capital (2002), "Business Case for New Nuclear Power Plants: Bringing Public and Private Resources together for Nuclear Energy", July 2002.

Stenzel, T. (2003), “Keeping the nuclear Option Open”, UK Parliamentary Office of Science and Technology Note 208.

Stirling, A. (2001), 'Science and precaution in the appraisal of electricity supply options', Journal of Hazardous Materials 86, 55-75, 2001.

Tarjanne R. and Rissanen S. (2000), "Nuclear power: least cost option for base-load electricity in Finland. The Uranium Institute 25th Annual Symposium, 30 August-1 September 2000, London.

Tolley G., and D. Jones (2004), “The Economic Future Of Nuclear Power,” A Study Conducted At The University Of Chicago, http://www.ne.doe.gov/reports/NuclIndustryStudy.pdf

Uranium Information Center (2004), “Uranium Markets”, Nuclear Issues Briefing Paper 36, October 2004.

von der Fehr, N.-H., E. Amundsen and L.Bergman (2005), “The Nordic Market: Signs of Stress?,” The Energy Journal, Special Issue, European Electricity Liberalisation, edited by David Newbery, Vol. 26 (4): 71-99.

World Nuclear Association (2005), “Plans for new reactors worldwide,” April 2005. 